\title{
Papers
}

\section{Risk factors for pre-eclampsia at antenatal booking: systematic review of controlled studies}

\author{
Kirsten Duckitt, Deborah Harrington
}

\begin{abstract}
Objective To determine the risk of pre-eclampsia associated with factors that may be present at antenatal booking.

Design Systematic review of controlled studies published 1966-2002.

Data synthesis Unadjusted relative risks were calculated from published data.

Results Controlled cohort studies showed that the risk of pre-eclampsia is increased in women with a previous history of pre-eclampsia (relative risk 7.19, 95\% confidence interval 5.85 to 8.83 ) and in those with antiphospholipids antibodies (9.72, 4.34 to 21.75$)$, pre-existing diabetes (3.56, 2.54 to 4.99$)$, multiple (twin) pregnancy $(2.93,2.04$ to 4.21$)$, nulliparity $(2.91,1.28$ to 6.61), family history (2.90, 1.70 to 4.93$)$, raised blood pressure (diastolic $\geq 80 \mathrm{~mm} \mathrm{Hg}$ ) at booking $(1.38,1.01$ to 1.87$)$, raised body mass index before pregnancy $(2.47,1.66$ to 3.67$)$ or at booking $(1.55,1.28$ to 1.88$)$, or maternal age $\geq 40(1.96,1.34$ to 2.87 , for multiparous women). Individual studies show that risk is also increased with an interval of 10 years or more since a previous pregnancy, autoimmune disease, renal disease, and chronic hypertension.

Conclusions These factors and the underlying evidence base can be used to assess risk at booking so that a suitable surveillance routine to detect pre-eclampsia can be planned for the rest of the pregnancy.
\end{abstract}

\section{Introduction}

Pre-eclampsia is a major cause of maternal and fetal mortality and morbidity. ${ }^{2}$ The incidence of pre-eclampsia is $2-10 \%$, depending on the population studied and definitions of pre-eclampsia. ${ }^{3}$ With the exception of smoking ${ }^{4}$ the literature has not been systematically reviewed for factors that predict the relative risk of developing pre-eclampsia. The recent National Institute for Clinical Excellence (NICE) guidelines on antenatal care have reduced the number of antenatal visits recommended for healthy woman at low risk. ${ }^{5}$ As the randomised controlled trials on which this recommendation was based were never powered to identify important outcomes such as mortality, and as the failure to identify and act on known risk factors at booking contributes to deaths from pre-eclampsia, ${ }^{1}$ it is important to define risk at the beginning of pregnancy.

We carried out a systematic review of published literature to reach an overall estimate for the risk of pre-eclampsia for each risk factor. This will provide an evidence base from which healthcare professionals can assess each pregnant woman's risk of pre-eclampsia at her booking visit and tailor her antenatal care according to need.

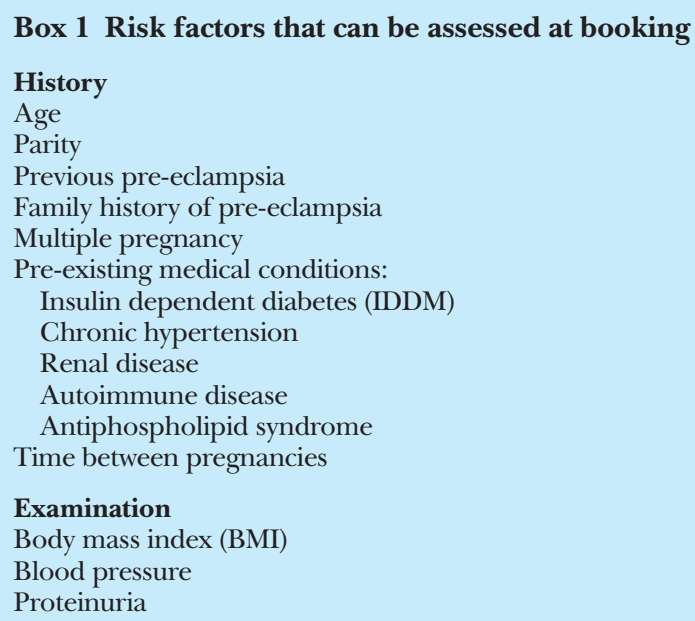

\section{Methods}

We searched Medline (1966 to July 2002) and Embase (1974 to July 2002) for publications in any language that considered the association between identified risk factors detectable at an antenatal booking visit (box 1) and the subsequent development of pre-eclampsia. A multidisciplinary guideline group set up to formulate evidence based guidelines on the community screening and detection of pre-eclampsia identified the risk factors. Our search terms included pre-eclampsia, preeclampsia, eclampsia, toxaemia, toxemia, meta-analysis, systematic review, risk factors, risk, causality, cohort studies, case-control studies. We also studied reference lists of published letters and classic review articles and asked experts in the field.

We initially selected studies with a cohort or case-control design that included pre-eclampsia (either as an outcome or to define cases) and the risk factors of interest. We assessed the quality of these studies with a checklist, adapted from Taggart et $\mathrm{al}^{6}{ }^{6}$ using participant selection, comparability of groups at baseline, and how the diagnosis of pre-eclampsia was made and according to what definition (box 2). We excluded any study that did not score in any category. We used study size, and the prospective or retrospective design of cohort studies, to score for heterogeneity. We independently extracted data from the included studies and resolved any differences by discussion.

Funnel plots for the main outcomes can be found on bmj.com 
Where data were available, we calculated the unadjusted relative risk with 95\% confidence intervals for each study and across studies using the random effects model with the MetaView statistical package (MetaView 4.01, Update Software, Oxford). We calculated the $I^{2}$ statistic $^{7}$ for combined studies. This estimates the proportion of total variation in study estimates that is due to heterogeneity and, unlike $\chi^{2}$, does not depend on the number of included studies. For some risk factors, we could not combine data from the included studies. We have described the results from these studies narratively and presented the published adjusted odds ratios or relative risks separately.

\section{Results}

We identified over 1000 studies, and, after screening abstracts, we read 149 papers. We excluded 34 because they were observational studies with no reference group or review articles, nine that reported eclampsia alone or did not separate out preeclampsia from pregnancy induced hypertension, 26 that did not concern the relevant risk factors, and 28 because they scored no points in one or more categories in the quality assessment. Fifty two studies (13 prospective cohort studies, 25 retrospective cohort studies, and 14 case-control studies) were therefore included in the systematic review. Of these, 23 had fewer than 100 participants in at least one of the groups. Table 1 shows details of the quality scores. A list of excluded studies is available on request.

\section{Box 2 Quality assessment of non-randomised studies (points scored) \\ Participant selection \\ Cohort studies \\ Selected cohort was representative of the general pregnant population (1) \\ Cohort was a selected group or the selection of the group was not described (0) \\ Case-control studies \\ Cases and controls drawn from the same population (1) \\ Cases and controls drawn from different sources or the selection of groups was not described (0)}

\section{Comparability of groups}

No differences between the groups explicitly reported (especially in terms of age, parity, pre-existing medical disease, singleton pregnancy) unless it was one of these variables that was under investigation, or such differences were adjusted for (2)

Differences between groups were not recorded (1)

Groups differed (0)

\section{Outcomes}

Definition of pre-eclampsia

Referenced definition (2)

Explicit definition that included new onset hypertension after

20 weeks' gestation with new proteinuria (1)

Pre-eclampsia not defined or unacceptable definition (0)

How the diagnosis of pre-eclampsia was made

Review of notes or prospective assignment (2)

ICD or database coding (1)

Process was not described (0)

Size

$>100$ participants in each group (2)

$<100$ participants in each group (1)

\section{Cohort design}

Prospective cohort design (2)

Retrospective design (1)
As expected, there was more evidence of heterogeneity, as assessed by the $I^{2}$ statistic, in the case-control studies than in the cohort studies. The available published adjusted odds ratios or relative risks, however, were similar to the unadjusted relative risks calculated in the meta-analysis.

Tables 2 and 3 summarise the results by risk factor. We found no data of sufficient quality on the presence of proteinuria at booking. There were also no data to calculate unadjusted relative risks for interval between births, existing hypertension, or existing renal disease. Published adjusted relative risks were available for the interval between births (table 3).

\section{Age}

All except one study, which looked at women aged $\geq 40$, failed to control or address differences at baseline (particularly preexisting chronic disease such as hypertension or diabetes). Women aged $\geq 40$ had approaching twice the risk of developing pre-eclampsia, whether they were primiparous or multiparous (relative risk 1.68, 95\% confidence interval 1.23 to 2.29, and 1.96, 1.34 to 2.87 , respectively). ${ }^{8}$ Nationwide US data suggest that the risk of pre-eclampsia increases by $30 \%$ for every additional year of age past $34 .{ }^{9}$ Young maternal age did not seem to affect the risk of developing pre-eclampsia, whichever cut off age was used.

\section{Parity}

Nulliparity almost triples the risk for pre-eclampsia (2.91, 1.28 to 6.61) (three cohort studies ${ }^{10-12}$ ); this is supported by adjusted odds ratios for nulliparity from two other cohort studies. ${ }^{13}{ }^{14}$ Women with pre-eclampsia are twice as likely to be nulliparous as women without pre-eclampsia $(2.35,1.80$ to 3.06$)$ (six case-control studies ${ }^{10}{ }^{15-19}$ ).

\section{Previous pre-eclampsia}

Women who have pre-eclampsia in a first pregnancy have seven times the risk of pre-eclampsia in a second pregnancy $(7.19,5.85$ to 8.83 ) (five cohort studies ${ }^{12-23}$ ). Women with pre-eclampsia in their second pregnancy are also more than seven times more likely to have a history of pre-eclampsia in their first pregnancy than women in their second pregnancy who do not develop preeclampsia $(7.61, \quad 4.3$ to 13.47$)$ (seven case-control studies $^{15} 1618$ 1924-26).

\section{Family history of pre-eclampsia}

A family history of pre-eclampsia nearly triples the risk of pre-eclampsia $\left(2.90,1.70\right.$ to 4.93 ) (two cohort studies ${ }^{27}$ ). Women with severe pre-eclamptic toxaemia are more likely to have a mother rather than a mother in law who had had pre-eclampsia. ${ }^{29}$

\section{Multiple pregnancy}

When a woman is pregnant with twins her risk of pre-eclampsia nearly triples (five cohort studies, 2.93, 2.04 to 4.21 ). ${ }^{1012} 183031$ Neither the chorionicity nor zygosity of the pregnancies alters this increased risk (data not shown ${ }^{32}{ }^{33}$ ). One study found that a triplet pregnancy nearly triples the risk of pre-eclampsia compared with a twin pregnancy $(2.83,1.25$ to 6.40$) .^{34}$

\section{Pre-existing medical conditions}

Insulin dependent diabetes-The likelihood of pre-eclampsia nearly quadruples if diabetes is present before pregnancy (3.56, 2.54 to 4.99) (three cohort studies ${ }^{12} 3135$ ).

Pre-existing hypertension-In a population based nested case-control study, Davies et al found that the prevalence of chronic hypertension was higher in women who developed preeclampsia than women who did not $(12.1 \% v 0.3 \%) .{ }^{25}$ McCowan et al compared outcomes in 129 women with chronic hypertension who did not develop superimposed pre-eclampsia with 26 
Table 1 Quality assessment of included studies (points scored, see box 2)

\begin{tabular}{|c|c|c|c|c|c|}
\hline Included study & Selection & Comparability & Size & Outcome $1^{*}$ & Outcome $2 \dagger$ \\
\hline \multicolumn{6}{|c|}{ Prospective cohort studies } \\
\hline Arngrimsson $1990^{27}$ & 1 & 1 & 1 & 1 & 2 \\
\hline Cincotta $1998^{28}$ & 1 & 1 & 1 & 1 & 2 \\
\hline Davies $1970^{25}$ & 1 & 2 & 2 & 1 & 2 \\
\hline Dukler $2001^{23}$ & 1 & 2 & 2 & 1 & 2 \\
\hline Garner $1990^{35}$ & 1 & 2 & 2 & 2 & 2 \\
\hline Hartikainen $1998^{14}$ & 1 & 2 & 2 & 1 & 2 \\
\hline Pattison $1993^{38}$ & 1 & 1 & 1 & 1 & 2 \\
\hline Sattar $2001^{55}$ & 1 & 2 & 2 & 1 & 2 \\
\hline Sibai $1986^{21}$ & 1 & 2 & 2 & 1 & 2 \\
\hline Sibai $1995^{54}$ & 1 & 2 & 2 & 1 & 2 \\
\hline Sibai $1997^{49}$ & 1 & 2 & 2 & 1 & 2 \\
\hline Thadhani $1999^{48}$ & 1 & 2 & 1 & 1 & 2 \\
\hline Yasuda $1995^{39}$ & 1 & 1 & 1 & 2 & 2 \\
\hline \multicolumn{6}{|c|}{ Retrospective cohort studies } \\
\hline Basso $2001^{45}$ & 1 & 2 & 2 & 2 & 1 \\
\hline Bianco $1996^{8}$ & 1 & 1 & 2 & 1 & 1 \\
\hline Bianco $1998^{46}$ & 1 & 2 & 2 & 1 & 1 \\
\hline Bowers $1999^{50}$ & 1 & 2 & 1 & 1 & 2 \\
\hline Bradford $1989^{56}$ & 1 & 2 & 1 & 1 & 2 \\
\hline Brown $1991^{57}$ & 1 & 1 & 2 & 2 & 2 \\
\hline Campbell $1985^{20}$ & 1 & 1 & 2 & 2 & 2 \\
\hline Conde-Agudelo ${ }^{44}$ & 1 & 2 & 2 & 1 & 1 \\
\hline Coonrod $1995^{10}$ & 1 & 1 & 1 & 1 & 1 \\
\hline Khan $1996^{13}$ & 1 & 2 & 2 & 1 & 2 \\
\hline Konje $1992^{58}$ & 1 & 1 & 2 & 2 & 2 \\
\hline Lawoyin $1996^{11}$ & 1 & 1 & 1 & 1 & 2 \\
\hline Lee $2000^{12}$ & 1 & 2 & 2 & 2 & 2 \\
\hline Makkonen $2000^{22}$ & 1 & 2 & 2 & 1 & 2 \\
\hline Martinell $1990^{37}$ & 1 & 2 & 1 & 1 & 2 \\
\hline Maxwell $2001^{32}$ & 1 & 2 & 1 & 2 & 2 \\
\hline McCowan $1996^{36}$ & 1 & 1 & 1 & 1 & 2 \\
\hline Reiss $1987^{53}$ & 1 & 2 & 1 & 1 & 2 \\
\hline Ros $1998^{31}$ & 1 & 2 & 2 & 2 & 1 \\
\hline Saftlas $1990^{9}$ & 1 & 2 & 2 & 2 & 1 \\
\hline Savvidou $2001^{33}$ & 1 & 2 & 2 & 2 & 2 \\
\hline Sebire $2001^{52}$ & 1 & 2 & 2 & 1 & 1 \\
\hline Skjaerven $2002^{43}$ & 1 & 2 & 2 & 1 & 2 \\
\hline Stamilo $2000^{19}$ & 1 & 2 & 1 & 2 & 2 \\
\hline Stone $1994^{16}$ & 1 & 2 & 1 & 1 & 2 \\
\hline \multicolumn{6}{|l|}{ Case-control studies } \\
\hline Banias $1992^{26}$ & 1 & 2 & 1 & 1 & 2 \\
\hline Branch $1989^{40}$ & 1 & 1 & 1 & 1 & 2 \\
\hline Chen $2000^{17}$ & 1 & 1 & 2 & 1 & 2 \\
\hline Dreyfus $2001^{42}$ & 1 & 2 & 2 & 1 & 2 \\
\hline Eskenazi $1991^{15}$ & 1 & 2 & 2 & 2 & 1 \\
\hline Fields $1996^{47}$ & 1 & 1 & 1 & 1 & 2 \\
\hline Moore $1983^{24}$ & 1 & 2 & 1 & 1 & 2 \\
\hline Odegard $2000^{18}$ & 1 & 1 & 2 & 1 & 2 \\
\hline Reiss $1987^{53}$ & 1 & 2 & 1 & 1 & 2 \\
\hline Santema $1995^{30}$ & 1 & 2 & 2 & 2 & 2 \\
\hline Skupski $1996^{34}$ & 1 & 2 & 1 & 2 & 2 \\
\hline Sletnes $1992^{41}$ & 1 & 1 & 1 & 1 & 2 \\
\hline Sutherland $1981^{29}$ & 1 & 2 & 2 & 1 & 2 \\
\hline Van Hoorn $2002^{51}$ & 1 & 1 & 1 & 2 & 2 \\
\hline
\end{tabular}

${ }^{*}$ Definition of pre-eclampsia.

tHow diagnosis of pre-eclampsia is made.

women with chronic hypertension who did. ${ }^{36}$ Those with superimposed pre-eclampsia had significantly higher rates of perinatal morbidity (odds ratio 8.8, 2.6 to 39.0), small for gestational age infants $(5.6,1.8$ to 16.0$)$, and delivery before 32 weeks $(15.0,5.7$ to 38.0 ). A diastolic blood pressure before 20 weeks of either $\geq 110 \mathrm{~mm} \mathrm{Hg}(5.2,1.5$ to 17.2$)$ or $\geq 100 \mathrm{~mm} \mathrm{Hg}$
(3.2, 1.0 to 7.8 ) is most predictive of the development of superimposed pre-eclampsia.

Renal disease-Davies et al also found that the prevalence of renal disease was higher in women who developed preeclampsia compared with those that did not $(5.3 \% v 1.8 \%))^{25}$ Only one study compared women with renal disease, due to a 
Table 2 Published and calculated relative risks and odds ratios for cohort studies

\begin{tabular}{|c|c|c|c|c|c|}
\hline & No of studies & No of women & Unadjusted relative risk $(95 \% \mathrm{Cl})$ & P & $\begin{array}{l}\text { Published risk (odds ratio or relative } \\
\text { risk), } 95 \% \text { CI (adjustment) }\end{array}$ \\
\hline Antiphospholipid antibodies $v$ none & $2^{38} 39$ & 1802 & $9.72(4.34$ to 21.75$)$ & $55.9 \%$ & NA \\
\hline Pre-existing diabetes $v$ none & $3^{123135}$ & 56968 & 3.56 (2.54 to 4.99 ) & $0 \%$ & $\begin{array}{l}5.58,2.72 \text { to } 11.43^{31} \text { (smoking status, } \\
\text { No of fetuses, season of birth, place of } \\
\text { birth) }\end{array}$ \\
\hline Previous pre-eclampsia $v$ none & $5^{1220-23}$ & 24620 & 7.19 (5.85 to 8.83$)$ & $0 \%$ & NA \\
\hline Family history $v$ no family history & $2^{2728}$ & 692 & 2.90 (1.70 to 4.93$)$ & $0 \%$ & NA \\
\hline Nulliparity $v$ multiparity & $3^{10-12}$ & 37988 & 2.91 (1.28 to 6.61$)$ & $94.3 \%$ & $\begin{array}{l}3.10,1.55 \text { to } 6.17^{13} \text { (age, result of } \\
\text { glucose challenge test); } 3.0,2.1 \text { to } 4.2^{14} \\
\text { (age, BMI, smoking status, education, } \\
\text { employment) }\end{array}$ \\
\hline Twin $v$ singleton pregnancy & $5^{1012183031}$ & 53028 & 2.93 (2.04 to 4.21$)$ & $72.7 \%$ & $\begin{array}{l}4.17,2.30 \text { to } 7.55^{31} \text { (smoking status, } \\
\text { diabetes, season of birth, place of birth) }\end{array}$ \\
\hline Triplet $v$ twin pregnancy & $1^{34}$ & 76 & 2.83 (1.25 to 6.40$)$ & - & NA \\
\hline Raised $v$ normal BMI at booking & $3^{49-51}$ & 4625 & 1.55 (1.28 to 1.88$)$ & $0 \%$ & $\begin{array}{l}1.9,0.7 \text { to } 4.8^{55} \text { (all parity, BMI } \geq 25 \text { ); } \\
9.3,2.0 \text { to } 48.0^{55} \text { (primiparas only, BMI } \\
\geq 25 \text { ) }\end{array}$ \\
\hline Raised $v$ normal BMI before pregnancy & $6^{12163146-48}$ & 64789 & 2.47 (1.66 to 3.67 ) & $85.9 \%$ & $\begin{array}{l}1.8,1.0 \text { to } 3.2^{14} \text { (age, parity, smoking } \\
\text { status, education, employment); } 3.14 \text {, } \\
1.44 \text { to } 6.83^{31} \text { (BMI } 26.1-29.0 \mathrm{v} \text { normal } \\
\text { BMI adjusted for smoking, place and } \\
\text { season of birth, diabetes); } 5.19,2.35 \text { to } \\
11.48^{31} \text { (BMI }>29.0 \mathrm{v} \text { normal BMI } \\
\text { adjusted for smoking, place, season of } \\
\text { birth, diabetes); RR } 2.1,1.0 \text { to } 4.6^{48} \\
\text { (BMI } \geq 30 \text { before pregnancy adjusted for } \\
\text { age, parity, diabetes, maternal and } \\
\text { paternal hypertension, smoking status, } \\
\text { history of raised cholesterol) }\end{array}$ \\
\hline $\begin{array}{l}\text { Systolic } \geq 130 \mathrm{~mm} \mathrm{Hg} v<130 \mathrm{~mm} \mathrm{Hg} \text { at } \\
\text { booking }\end{array}$ & $1^{18}$ & 906 & 2.37 (1.78 to 3.15$)$ & - & $\begin{array}{l}3.6,2.0 \text { to } 6.6^{18} \text { (previous } \\
\text { pre-eclampsia, parity, maternal weight, } \\
\text { smoking status, No of fetuses) }\end{array}$ \\
\hline $\begin{array}{l}\text { Diastolic } \geq 80 \mathrm{~mm} \mathrm{Hg} V<80 \mathrm{~mm} \mathrm{Hg} \text { at } \\
\text { booking }\end{array}$ & $1^{18}$ & 907 & 1.38 (1.01 to 1.87$)$ & - & $\begin{array}{l}1.8,0.7 \text { to } 4.6^{18} \text { (previous } \\
\text { pre-eclampsia, parity, maternal weight, } \\
\text { smoking status, No of fetuses) }\end{array}$ \\
\hline \multicolumn{6}{|l|}{ Maternal age (years): } \\
\hline$\leq 17 v>17$ & $1^{56}$ & 161 & 2.98 (0.39 to 22.76) & - & NA \\
\hline$\leq 16 v>16$ & $4^{10535758}$ & 11589 & 1.24 (0.69 to 2.23) & $78.3 \%$ & NA \\
\hline$\leq 19 v>19$ & $3^{111231}$ & 15295 & 1.02 (0.59 to 1.74$)$ & $23.0 \%$ & NA \\
\hline$\geq 35 v<35$ & $3^{111217}$ & 65314 & 0.64 (0.03 to 13.33$)$ & $99.8 \%$ & $\begin{array}{l}2.5,1.5 \text { to } 4.1^{14} \text { (parity, BMI, smoking } \\
\text { status, education, employment); } 1.09 \text {, } \\
1.02 \text { to } 1.17^{13} \text { (gravidity and glucose } \\
\text { challenge test result) }\end{array}$ \\
\hline Age $\geq 40 v<40$ multiparas & $1^{8}$ & 3140 & 1.96 (1.34 to 2.87$)$ & - & NA \\
\hline Age $\geq 40 v<40$ primiparas & $1^{8}$ & 5242 & 1.68 (1.23 to 2.29$)$ & - & NA \\
\hline For each year increase in age & - & - & - & - & RR $1.3,1.0$ to $1.5^{9}$ \\
\hline$>59$ 1 18-23 months between births & - & - & - & - & RR $1.83,1.72$ to $1.94^{44}$ \\
\hline For each year increase in interval & - & - & - & - & $\begin{array}{l}1.12,1.11 \text { to } 1.13^{43} \text { (change of partner, } \\
\text { maternal age, year of delivery) }\end{array}$ \\
\hline
\end{tabular}

$\mathrm{BMI}=$ body mass index; $\mathrm{NA}=$ not available; RR=relative risk.

history of urinary tract infections, with a prospective control population matched for age, parity, smoking, and date of delivery. ${ }^{37}$ In 69 continuing pregnancies, $6.7 \%(2 / 30)$ of the women who had urinary tract infections developed preeclampsia (both primigravida with scarred kidneys) compared with $2.6 \%(1 / 39)$ of women in the control group.

Chronic autoimmune disease-In a matched case-control study Stamilio et al found that women who developed pre-eclampsia were more likely to have an autoimmune disease (relative risk $6.9,1.1$ to 42.3$).^{19}$
Antiphospholipid syndrome-The presence of antiphospholipid antibodies (anticardiolipin antibodies or lupus anticoagulant or both) significantly increases the risk of developing pre-eclampsia (9.72, 4.34 to 21.75 ) (two cohort studies ${ }^{38}$ ). However, when women who developed pre-eclampsia were matched with women who did not, they were no more likely to be positive for lupus anticoagulant or anticardiolipin antibodies $(6.12,0.35$ to 108.35) (three case-control studies ${ }^{40} 4142$ ).

Table 3 Case control studies: pre-eclampsia

\begin{tabular}{|c|c|c|c|c|}
\hline Risk factor & No of studies & No of women & Unadjusted relative risk $(95 \% \mathrm{Cl})$ & $r^{2}$ \\
\hline Previous pre-eclampsia & $7^{1516} 18192425$ & 22352 & 7.61 (4.30 to 13.47$)$ & $65.7 \%$ \\
\hline Family history in mother & $1^{29}$ & 262 & 3.60 ( 1.49 to 8.67$)$ & - \\
\hline Nulliparity & $6^{1015-19}$ & 304559 & 2.35 (1.80 to 3.06$)$ & $97.3 \%$ \\
\hline Antiphospholipid antibodies & $3^{40-42}$ & 760 & $6.12(0.35$ to 108.35$)$ & $81.5 \%$ \\
\hline
\end{tabular}




\section{Time between pregnancies}

In a Norwegian population study Skjaerven et al studied 551478 women who had two or more singleton deliveries and 209423 women who had three or more singleton deliveries. ${ }^{43}$ The association between risk of pre-eclampsia and interval was more significant than the association between risk and change of partner. The risk in a second or third pregnancy was directly related to the time elapsed since the previous delivery. When the interval was 10 years or more the risk of pre-eclampsia was about the same as that in nulliparous women. After adjustment for the presence or absence of a change of partner, maternal age, and year of delivery, the probability of pre-eclampsia was increased by 1.12 for each year increase in the interval (odds ratio 1.12, 1.11 to 1.13$)$.

A cross sectional study from Uruguay found that women with more than 59 months between pregnancies had significantly increased risks of pre-eclampsia (relative risk $1.83,1.72$ to 1.94) compared with women with intervals of 18-23 months. ${ }^{44}$

A Danish cohort study found that a long interval between pregnancies was associated with a significantly higher risk of pre-eclampsia in a second pregnancy when pre-eclampsia had not been present in the first pregnancy and paternity had not changed. ${ }^{45}$

\section{Body mass index}

Although the studies that looked at body mass index before pregnancy all used different ranges, they all showed effects in the same direction, suggesting an overall doubling of risk of pre-eclampsia with a raised body mass index $(2.47,1.66$ to 3.67$)$ (six studies ${ }^{12} 16$ 31 46-48). One cohort study showed that women with a body mass index $>35$ before pregnancy had over four times the risk of pre-eclampsia compared with women with a pre-pregnancy body mass index of $19-27(4.39,3.52,5.49) .{ }^{46}$ We combined all studies that looked at raised compared with normal body mass index at booking and found that the risk of pre-eclampsia is increased by $50 \%{ }^{49-51}$ Notably, a body mass index $>35$ at booking doubles the pre-eclampsia risk (one cohort study, 2.12, 1.56 to 2.88). ${ }^{49}$ Confounding factors can affect the relation between body mass index and pre-eclampsia as women with raised body mass index may be older and more at risk of chronic hypertension. However, published odds ratios that have been adjusted to take some of these factors into account still suggest an increased risk with a raised body mass index (see table 2). A study comparing low and normal body mass index at booking found that the risk of pre-eclampsia was significantly reduced with a body mass index $<20$ (odds ratio $0.76,0.62$ to 0.92 , adjusted for diabetes and smoking). ${ }^{52}$

\section{Blood pressure at booking}

Reiss et al matched 30 women with pre-eclampsia for age, race, and parity with normotensive control women ${ }^{53}$ Both systolic and diastolic blood pressures were significantly higher in the first trimester for women who later developed pre-eclampsia. The study did not define cut off values.

Sibai et al found that higher systolic and diastolic blood pressures at the first visit were associated with an increased incidence of pre-eclampsia $(3.8 \%$ in women with diastolic blood pressure of $<55 \mathrm{~mm} \mathrm{Hg}, 7.4 \%$ in those with diastolic blood pressure $70-84 \mathrm{~mm} \mathrm{Hg}){ }^{54}$ However, their recruitment was limited to women with a first blood pressure reading of $\leq 135 / 85 \mathrm{~mm} \mathrm{Hg}$.

In a population based nested case-control study Odegard et al found that a systolic blood pressure $\geq 130 \mathrm{~mm} \mathrm{Hg}$ compared with $<110 \mathrm{~mm} \mathrm{Hg}$ at the first visit before 18 weeks was significantly associated with the development of pre-eclampsia later in pregnancy (adjusted odds ratio 3.6, 2.0 to 6.6). ${ }^{18}$ The association with a diastolic pressure $\geq 80 \mathrm{~mm} \mathrm{Hg}$ compared with $<60 \mathrm{~mm}$ $\mathrm{Hg}$ was similar but not significant (1.8, 0.7 to 4.6).

In a case-control study Stamilio et al found that a mean arterial pressure $>90 \mathrm{~mm} \mathrm{Hg}$ at the first prenatal visit was significantly associated with the development of severe pre-eclamptic toxaemia (relative risk $3.7,2.1$ to 6.6 ). ${ }^{19}$

\section{Confirmed proteinuria at booking}

We did not find any studies with an appropriate control group that examined the incidence of pre-eclampsia in women who have proteinuria at booking but no previously known renal disease.

\section{Discussion}

In this systematic review of controlled studies we found that antiphospholipid antibodies, a history of pre-eclampsia, preexisting diabetes, multiple pregnancy, family history, nulliparity, a raised BMI before pregnancy or at booking, maternal age $>40$, renal disease, hypertension, $\geq 10$ years since the last pregnancy, and raised blood pressure at booking all increased the risk of a woman developing pre-eclampsia.

We reviewed only published studies, and unpublished studies may contain valid results that conflict with our conclusions. This is of particular concern in a meta-analysis of observational studies as there is a greater tendency towards publication bias than there is with randomised controlled trials. ${ }^{59}$ Because the peer review process is an important means of ensuring quality, however, possibly only published data and studies should be used.$^{60}$ Publication bias is always a concern for systematic reviews. Funnel plots for the risk factors where over three studies were included were symmetrical for low maternal age, parity, previous pre-eclampsia, pre-existing diabetes, and body mass index before pregnancy (see figs A-H on bmj.com). Some researchers may not have reported on variables that they studied but that did not show an association with pre-eclampsia.

Pre-eclampsia was seldom divided into early and late onset, nor were results presented for onset of pre-eclampsia or delivery in relation to gestational age. We may therefore have underestimated the importance of risk factors for early onset pre-eclampsia, a type with considerable maternal and perinatal morbidity and mortality. ${ }^{26} 61$

Although we examined the role of individual risk factors, little is known about the association between them. For instance, is a low risk multiparous woman under 40 who did not have pre-eclampsia in her first pregnancy at an increased risk of preeclampsia because she has a family history? Similarly as most of the studies concerning body mass index did not separate out their results for parity or control for previous history, it is also unclear whether a raised pre-pregnancy or booking weight or body mass index is less of a risk factor in a multiparous woman who has not had pre-eclampsia in her first pregnancy.

Because we did not identify any controlled studies of sufficient quality we cannot draw any conclusions about proteinuria at booking, although the association of proteinuria with renal disease, which is a risk factor, suggests that it is probably important.

The risk factors that we have identified can be used to assess risk at the booking visit, so that a suitable surveillance routine to detect pre-eclampsia can be planned for the rest of the pregnancy, as recommended by the recent NICE guideline on antenatal care ${ }^{5}$ and the new pre-eclampsia community guideline (PRECOG) guideline. ${ }^{62}$ 


\section{What is already known on this topic}

Various factors, which can be ascertained at the first antenatal or booking visit, are thought to increase the risk of a woman developing pre-eclampsia during pregnancy

\section{What this study adds}

The most significant risk factors for developing pre-eclampsia are a history of pre-eclampsia and the presence of antiphospholipid antibodies

Pre-existing diabetes and a pre-pregnancy BMI of $\geq 35$ almost quadruple the risk; nulliparity, a family history of pre-eclampsia, and twin pregnancy almost triple the risk; and maternal age $\geq 40$, a booking BMI of $\geq 35$, and a systolic blood pressure $\geq 130$ at booking double the risk

Pre-existing hypertension, renal disease, chronic autoimmune disease, and $\geq 10$ years between pregnancies increase the risk but it is not clear by how much

We thank Jill Mollison from the Centre for Statistics in Medicine, Oxford who provided statistical advice.

Contributors: The original idea for the article came from a meeting of the PRECOG (pre-eclampsia community guideline) development group. The study was designed by KD. Data were extracted independently by KD and $\mathrm{DH}$. The paper was written by $\mathrm{KD}$ and reviewed by $\mathrm{DH}$. $\mathrm{KD}$ is guarantor.

Funding: The photocopying of some of the articles was paid for by the charity APEC (Action on Pre-eclampsia).

Competing interests: None declared.

Ethical approval: Not needed.

1 Confidential Enquiries into Maternal Deaths. Why mothers die 1997-1999. The fifth report of the confidential enquiries into maternal deaths in the United Kingdom. London: Royal College of Obstetricians and Gynaecologists Press, 2001.

2 Confidential Enquiry into Stillbirths and Deaths in Infancy. 8th annual report. London: Maternal and Child Health Research Consortium, 2001

3 World Health Organization International Collaborative Study of Hypertensive Disorders of Pregnancy. Geographic variation in the incidence of hypertension in pregnancy. Am J Obst Gynecol 1988;158:80-3.

4 Conde-Agudelo A, Althabe F, Belizan JM, Kafury-Goeta AC. Cigarette smoking during pregnancy and risk of pre-eclampsia: a systematic review. Am J Obstet Gynecol 1999;181:1026-35.

5 National Institute for Clinical Excellence. NICE Guideline CG6 Antenatal care-routine care for the healthy pregnant woman. London: NICE, 2003.

6 Taggart DP, D'Amico R, Altman DG. Effect of arterial revascularisation on survival: a systematic review of studies

7 Higrins JPT, Thompson SG. Ouantifying heterogeneity in a meta-analysis. Stat Med 2002;21:1539-58.

8 Bianco A, Stone J, Lynch L, Lapinski R, Berkowitz G, Berkowitz RL. Pregnancy outcome at age 40 and older. Obstet Gynecol 1996;87:917-22.

9 Saftlas AF, Olson DR, Franks Al, Atrash HK, Pokras R. Epidemiology of preeclampsia and eclampsia in the United states, 1979-1986. Am J Obstet Gynecol 1990;163:460-5.

10 Coonrod DV, Hickok DE, Zhu K, Easterling TR, Daling JR. Risk factors for preeclampsia in twin pregnancies: a population-based cohort study. Obstet Gynecol 1995;85:64550.

11 Lawoyin TO, Ani F. Epidemiologic aspects of pre-eclampsia in Saudi Arabia. East Afr Med J 1996;73:404-6.

12 Lee CJ, Hsieh TT, Chiu TH, Chen KC, Lo LM, Hung TH. Risk factors for pre-eclampsia in an Asian population. Int J Gynecol Obstet 2000;70:327-33.

13 Khan KS, Daya S. Plasma glucose and pre-eclampsia. Int J Gynecol Obstet 1996;53:111-6

13 Khan KS, Daya S. Plasma glucose and pre-eclampsia. Int J Gynecol Obstet 1996;53:111-6. ciations and outcomes of pregnancies with hypertensive disorders. Hypertens Pregnancy 1998;17:31-41.

15 Eskenazi B, Fenster L, Sidney SA. Multivariate analysis of risk factors for preeclampsia. JAMA 1991;266:237-41.

16 Stone JL, Lockwood CJ, Berkowitz GS, Alvarez M, Lapinski R, Berkowitz RL. Risk factors for severe preeclampsia. Obstet Gynecol 1994;83:357-61.

17 Chen CL, Cheng Y, Wang PH, Juang CM, Chiu LM, Yang MJ, et al. Review of pre-eclampsia in Taiwan: a multi-institutional study. Zhonghua Yi Xue Za Zhi (Taipei) 2000;63:869-75.

18 Odegard RA, Vatten LJ, Nilsen ST, Salvesen KA, Austgulen R. Risk factors and clinical manifestations of pre-eclampsia. Br J Obstet Gynaecol 2000;107:1410-6.

19 Stamilio DM, Sehdev HM, Morgan MA, Propert K, Macones GA. Can antenatal clinical and biochemical markers predict the development of severe preeclampsia? Am J Obstet Gynecol 2000;182:589-94

20 Campbell DM, MacGillivray I, Carr-Hill R. Pre-eclampsia in second pregnancy. Br J Obstet Gynaecol 1985;92:131-40
21 Sibai BM, El Nazer A, Gonzalez-Ruiz A. Severe preeclampsia-eclampsia in young primigravid women: subsequent pregnancy outcome and remote prognosis. Am J Obstet Gynecol 1986;155:1011-6.

22 Makkonen N, Heinonen S, Kirkinen P. Obstetric prognosis in second pregnancy after preeclampsia in first pregnancy. Hypertens Pregnancy 2000;19:173-81.

23 Dukler D, Porath A, Bashiri A, Erez O, Mazor M. Remote prognosis of primiparous women with preeclampsia. EurJ Obstet Gynecol Reprod Biol 2001;96:69-74.

24 Moore MP, Redman CW. Case-control study of severe pre-eclampsia of early onset BMJ 1983;287:580-3.

25 Davies AM, Czaczkes JW, Sadovsky E, Prywes R, Weiskopf P, SterkVV. Toxemia of pregnancy in Jerusalem I. Epidemiological studies of a total community. Isr J Med Sci 1970;6:253-66.

26 Banias BB, Devoe LD, Nolan TE. Severe preeclampsia in preterm pregnancy between 26 and 32 weeks' gestation. Am J Perinatol 1992;9:357-60.

27 Arngrimsson R, Bjornsson S, Geirsson RT, Bjornsson H, Walker JJ, Snaedal G. Genetic and familial predisposition to eclampsia and pre-eclampsia in a defined population. $B r$ J Obstet Gynaecol 1990;97:762-9.

28 Cincotta RB, Brennecke SP. Family history of pre-eclampsia as a predictor for pre-eclampsia in primigravidas. Int J Gynaecol Obstet 1998;60:23-7.

29 Sutherland A, Cooper DW, Howie PW, Liston WA, MacGillivray I. The incidence of severe pre-eclampsia amongst mothers and mothers-in-law of pre-eclamptics and controls. BrJ Obstet Gynaecol 1981;88:785-91.

30 Santema JG, Koppelaar I, Wallenburg HC. Hypertensive disorders in twin pregnancy. EurJ Obstet Gynecol Reprod Biol 1995;58:9-13.

31 Ros HS, Cnattingius S, Lipworth L. Comparison of risk factors for preeclampsia and gestational hypertension in a population-based cohort study. Am J Epidemiol 1998;147;11(suppl):1062-70.

32 Maxwell CV, Lieberman E, Norton M, Cohen A, Seely EW, Lee-Parritz A. Relationship of twin zygosity and risk of preeclampsia. Am J Obstet Gynecol 2001;185:819-21.

33 Savvidou MD, Karanastasi E, Skentou C, Geerts L, Nicolaides KH. Twin chorionicity and pre-eclampsia. Ultrasound Obstet Gynecol 2001;18:228-31.

34 Skupski DW, Nelson S, Kowalik A, Polaneczky M, Smith-Levitin M, Hutson JM Rosenwaks Z. Multiple gestations from in vitro-fertilization: Successful implantation alone is not associated with subsequent pre-eclampsia. Am J Obstet Gynecol 1996;175:1029-32.

35 Garner PR, D'Alton ME, Dudley DK, Huard P, Hardie M. Preeclampsia in diabetic pregnancies. Am J Obstet Gynecol 1990;163:505-8.

36 McCowan LM, Buist RG, North RA, Gamble G. Perinatal morbidity in chronic hypertension. Br J Obstet Gynaecol 1996;103:123-9.

37 Martinell J, Jodal U, Lidin-Janson G. Pregnancies in women with and without renal scarring after urinary infections in childhood. BMJ 1990;300:840-4

38 Pattison NS, Chamley LW, McKay EJ, Liggins GC, Butler WS. Antiphospholipid antibodies in pregnancy: prevalence and clinical associations. Br J Obstet Gynaecol 1993;100:909-13.

39 Yasuda M, Takakuwa K, Tokunaga A, Tanaka K. Prospective studies of the association between anticardiolipin antibody and outcome of pregnancy. Obstet Gynecol 1995;86:555-9.

40 Branch DW, Andres R, Digre KB, Rote NS, Scott JR. The association of antiphospholipid antibodies with severe preeclampsia. Obstet Gynecol 1989;73:541-5.

41 Sletnes KE, Wisloff F, Moe N, Dale PO. Antiphospholipid antibodies in pre-eclamptic women: relation to growth retardation and neonatal outcome. Acta Obstet Gynecol Scand 1992;71:112-7.

42 Dreyfus M, Hedelin G, Kutnahorsky R, Lehmann M, Vivelle B, Langer B, et al. Antiphospholipid antibodies and preeclampsia: a case-control study. Obstet Gynecol 2001;97:29-34.

43 Skjaerven R, Wilcox AJ, Lie RT. The interval between pregnancies and the risk of preeclampsia. N Engl J Med 2002;346:33-8.

44 Conde-Agudelo A, Belizan JM. Maternal morbidity and mortality associated with interpregnancy interval: cross sectional study. BMJ 2000;321:1255-9.

45 Basso O, Christensen K, Olsen J. Higher risk of pre-eclampsia after change of partner. An effect of longer interpregnancy intervals? Epidemiology 2001;12:624-9.

46 Bianco AT, Smilen SW, Davis Y, Lopez S, Lapinski R, Lockwood CJ. Pregnancy outcome and weight gain recommendations for the morbidly obese woman. Obstet Gynecol 1998;91:97-102.

47 Fields SJ, Vainder M, Livshits G, Merlob P, Sirotta L. Obesity and the risk of toxaemia of pregnancy. Ann Hum Biol 1996;23:353-62.

48 Thadhani R, Stampfer MJ, Hynter DJ, Manson JE, Solomon CG, Curhan GC. High body mass index and hypercholesterolaemia: risk of hypertensive disorders of body mass index and hypercholestero

49 Sibai BM, Ewell M, Levine RJ, Klebanoff MA, Esterlitz J, Catalano PM, et al. Risk factors associated with preeclampsia in healthy nulliparous women. The Calcium for Preeclampsia Prevention (CPEP) Study Group. Am J Obstet Gynecol 1997;177:1003-10

50 Bowers D, Cohen WR. Obesity and related pregnancy complications in an inner-city clinic. J Perinatol 1999;19:216-9.

51 Van Hoorn J, Dekker G, Jeffries B. Gestational diabetes versus obesity as risk factors for pregnancy-induced hypertensive disorders and fetal macrosomia. Aust N Z J Obstet Gynaecol 2002;42:29-34.

52 Sebire NJ, Harris J, Regan L, Robinson S. Is maternal underweight really a risk factor for adverse pregnancy outcome? A population-based study in London. $\mathrm{Br} J$ Obstet Gynaecol 2001;108:61-6.

53 Reiss RE, O'Shaughnessy RW, Quilligan TJ, Zuspan FP. Retrospective comparison of blood pressure course during preeclamptic and matched control pregnancies. Am J Obstet Gynecol 1987;156:894-8.

54 Sibai BM, Gordon T, Thom E, Caritis SN, Klebanoff M, McNellis D, et al. Risk factors for preeclampsia in healthy nulliparous women: a prospective multicenter study. Am J Obstet Gynecol 1995;172:642-8.

55 Sattar N, Clark P, Holmes A, Lean MEJ, Walker I, Greer IA. Antenatal waist circumference and hypertension risk. Obstet Gynecol 2001;97:268-71.

56 Bradford JA, Giles WB. Teenage pregnancy in western Sydney. Aust N ZJ Obstet Gynaecol 1989;29:1-4.

57 Brown HL, Fan YD, Gonsoulin WJ. Obstetric complications in young teenagers. S Med J 1964;84:46-8. 
58 Konje JC, Palmer A, Watson A, Hay DM, Imrie A, Ewings P. Early teenage pregnancies in Hull. BrJ Obstet Gynaecol 1992;99:969-73.

59 Easterbrook PJ, Berlin JA, Gopalan R, Matthews DR. Publication bias in clinical research. Lancet 1991;337:867-72

60 Chalmers TC, Levin H, Sacks HS. Meta-analysis of clinical trials as a scientific discipline. I: control of bias and comparison with large co-operative trials. Stat Med 1987;6:315-25.

61 Mattar F, Sibai BM. Eclampsia. VIII. Risk factors for maternal morbidity. Am J Obstet Gynecol 2000;182:307-12.

62 Milne F, Redman C, Walker J, Baker P, Bradley J, Cooper C, et al. The pre-eclampsia community guideline (PRECOG): how to screen for and detect onset of pre-eclampsia in the community. BMJ 2005 (in press).
(Accepted 27 January 2005)

doi 10.1136/bmj.38380.674340.E0

Department of Obstetrics and Gynaecology,John Radcliffe Hospital, Oxford OX3 9DU

Kirsten Duckitt consultant obstetrician

Deborah Harrington subspecialty trainee in maternal and fetal medicine

Correspondence to: K Duckitt Kduckitt@doctors.org.uk 